\title{
Correction to: Past and future hydrogeological risk assessment under climate change conditions over urban settlements and infrastructure systems: the case of a sub-regional area of Piedmont, Italy
}

\section{Marta Ellena ${ }^{1,2} \cdot$ Ricciardi Guglielmo $^{3} \cdot$ Barbato Giuliana $^{1} \cdot$ Bufa Alessandra $^{3}$. Villani Veronica ${ }^{1} \cdot$ Mercogliano Paola $^{1}$}

Published online: 4 January 2021

(c) Springer Nature B.V. 2021

\section{Correction to: Natural Hazards (2020) 102:275-305 https://doi.org/10.1007/s11069-020-03925-w}

The original article was published with an error to the corresponding author's name. The author group and the publisher request the correct name, Marta Ellena, be noted and cited for the work. This correction stands to correct the original article.

The original article can be found online at https://doi.org/10.1007/s11069-020-03925-w.

\section{Marta Ellena}

marta.ellena@cmcc.it

1 Regional Models and Geo-Hydrological Impact Division, Fondazione Centro Euro-Mediterraneo sui Cambiamenti Climatici (CMCC), 81043 Capua, Italy

2 Department of Environmental Sciences, Informatics and Statistics, Università Ca'Foscari Venezia, 3246 Venice, Italy

3 Istituto Italiano di Ricerca e Sviluppo (ISIRES), Turin, Italy 